\title{
The Importance of Comparative Psychology for Developmental Science
}

\author{
Katja Liebal $^{\mathrm{a}, \mathrm{b}, \mathrm{c}, *}$ and Daniel B.M. Haun ${ }^{\mathrm{b}, \mathrm{c}, \mathrm{d}}$ \\ ${ }^{a}$ Department of Education and Psychology, Evolutionary Psychology/Languages of Emotion, Freie Universität Berlin, \\ Berlin, Germany \\ ${ }^{\mathrm{b}}$ Department of Psychology, University of Portsmouth, Portsmouth, UK \\ ${ }^{\mathrm{c}}$ Max Planck Institute for Evolutionary Anthropology, Leipzig, Germany \\ ${ }^{\mathrm{d}}$ Max Planck Institute for Psycholinguistics, Nijmegen, Netherlands
}

\begin{abstract}
The aim of this essay is to elucidate the relevance of cross-species comparisons for the investigation of human behavior and its development. The focus is on the comparison of human children and another group of primates, the non-human great apes, with special attention to their cognitive skills. Integrating a comparative and developmental perspective, we argue, can provide additional answers to central and elusive questions about human behavior in general and its development in particular: What are the heritable predispositions of the human mind? What cognitive traits are uniquely human? In this sense, Developmental Science would benefit from results of Comparative Psychology.
\end{abstract}

\section{Keywords}

development, cognitive skills, great apes, primates, comparative psychology

\section{What is Comparative Psychology?}

Comparative Psychology investigates the mental processes of different animal species, with the majority of research contrasting humans to various other animals. Charles Darwin's theory of evolution (1859) is central to this field, since it emphasis the phylogenetic continuity of human and nonhuman life. The central premise of Comparative Psychology is the idea that cognitive processes are biological adaptations with evolutionary histories, allowing for a mapping of cognitive similarities and differences across species (Haun, Jordan, Vallortigara, \& Clayton, 2010). In recent years, the study of non-human animal species and particularly of non-human great apes in

\footnotetext{
*Address for correspondence

Katja Liebal, Freie Universität Berlin, Cluster Languages of Emotion, Department of Education and Psychology, Evolutionary Psychology, Habelschwerdter Allee 45, 14195 Berlin, Germany. E-mail: katja.liebal@fu-berlin.de
}

comparison to humans has informed our current understanding of the development and evolution of human cognition (Johnson-Pynn, Fragaszy, \& CumminsSebree, 2003; Tomasello \& Call, 1997).

\section{Who are the Great Apes?}

Humans are primates - as are the other great apes (Groves, 2001). Most scholars consider humans as one species of great apes (Goodman, 1999), but this is still a matter of debate. Comparative Psychology usually considers four species of non-human great apes: bonobos, chimpanzees, gorillas, and orangutans. Chimpanzees and bonobos are the closest relatives of humans, since they split from the shared lineage with humans only 56 million years ago (Adachi \& Hasegawa, 1995). Both species live in Africa divided by the Congo River with chimpanzees living in West and Central Africa, while bonobos are restricted to the Democratic Republic of 
the Congo. They live in complex social groups and feed on fruits and foliage mainly. Chimpanzees have additionally been documented to hunt and eat other animals including monkeys. Gorillas also live in Africa, but as opposed to chimpanzees and bonobos, they live in smaller, more stable groups with one dominant male and his several females and offspring. They also spend more time on the ground and mainly feed on leaves and grass. Orangutans are the only nonhuman great apes that live in Asia. They are the most arboreal species and are also characterized by a semi-solitary lifestyle (Rowe, Goodall, \& Mittermeier, 1996). The majority of comparative studies, however, is conducted in captive settings in zoos, laboratories, or sanctuaries.

\section{What are the Heritable Predispositions of the Human Mind?}

Comparative Psychology can provide proof of concept that functional and complex cognitive skills can be in place at birth without further specific experiential input. In the early days of Comparative Psychology, controlled-rearing studies with non-human animals established that certain cognitive abilities can be present at birth. For example, the famous 'visual cliff' studies demonstrated that the ability to judge depth through motion parallax is functional not only in very young infants, but also at birth in a variety of animal species (Gibson \& Walk, 1960), bolstering the belief that the same capacity is innate in humans.

However, even if certain capacities and preferences are inherited, they might not be present at birth, but may only emerge later in life. Comparative Psychology also allows us to ask whether any late-blooming human cognitive capacity might be heritable: Comparisons between humans and our closest living phylogenetic relatives, the great apes, offer ways to investigate the evolutionary history of human cognitive skills and thereby indirectly argue for the heritability of certain cognitive traits (Haun et al., 2010). If a trait is present in all extant descendants of a common evolutionary ancestor, this trait is, with a measurable likelihood, inherited from that last common ancestor. By providing access to our own immediate evolutionary history, great apes are arguably one of the most important resources of Comparative Psychology. Thus below, we will focus on the cognitive skills of humans and contrast them with those of our closest phylogenetic relatives, the great apes.

\section{What Cognitive Traits are Uniquely Human?}

A vast body of research has systematically compared humans other great apes in regard to a variety of cognitive and communicative skills, such as causal knowledge and learning (Horner \& Whiten, 2005; Tennie, Call, \& Tomasello, 2006), mental rehearsal (Dunbar, McAdam, \& O'Connell, 2005), tool use (Hanus, Mendes, Tennie, \& Call, 2011), spatial representation (Haun, Call, Janzen, \& Levinson, 2006), prosocial behavior (Warneken \& Tomasello, 2006), cooperation (Rekers, Haun, \& Tomasello, 2011), gestural communication (Liebal, Mueller, \& Pika, 2007) and perspective taking (Kaminski, Call, \& Tomasello, 2008) to name but a few.

For example, a recent study showed that all nonhuman great ape species and human children successfully track invisible object displacements during visible rotations of a surface platform (Okamoto-Barth \& Call, 2008). Thus, following the argument laid out above, this skill appears to be part of the common evolutionary history in all extant great apes. By inference, the skill to infer invisible displacement of objects based on surface rotation is heritable in human and non-human great apes. However, in a slight variation of this study, the rotation of the surface platform was invisible. Hence, individuals had to rely on feature cues of the cups or the surface to infer the object displacement. In this scenario, only human children above five years of age, but not younger children and no other great apes, succeeded (Okamoto-Barth \& Call, 2008). Thus, while all tested species, including humans, share basic abilities, only human children from a certain age onwards solve a more complex version of the same task. Similar to this experiment, many recent studies, in particular in the physical domain, indicate that human and non-human great apes share many of their basic cognitive skills and that differences between human children and other apes are not as categorical as previously suggested.

In the social cognitive domain, however, very young human already show more sophisticated skills than other great apes (Herrmann, Call, Hernández-Lloreda, Hare, \& Tomasello, 2007). Hence the growing difference between humans and other great apes across the human lifespan might build on an early head start based on superior social cognitive skills that allow privileged access to information provided by others. Thus, Comparative Psychology offers a methodological approach to take a more differentiated, more critical and historical perspective on the species-typical aspects of human development (Johnson-Pynn et al., 2003). 


\section{References}

Adachi, J., \& Hasegawa, M. (1995). Improved dating of the human/chimpanzee separation in the mitochondrial DNA tree: Heterogeneity among amino acid sites. Journal of Molecular Evolution, 40, 622-628.

Darwin, C. (1859). On the origin of species by means of natural selection. London, UK: John Murray.

Dunbar, R., McAdam, M., \& O'Connell, S. (2005). Mental rehearsal in great apes (Pan troglodytes and Pongo pygmaeus) and children. Behavioural Processes, 69, 323-330.

Gibson, E. J., \& Walk, R. D. (1960). The visual cliff. Scientific American, 202, 64-71.

Goodman, M. (1999). The genomic record of Humankind's evolutionary roots. American Journal of Human Genetics, 64, 31-39.

Groves, C. (2001). Primate taxonomy. Washington, DC: Smithsonian Institution Press.

Hanus, D., Mendes, N., Tennie, C., \& Call, J. (2011). Comparing the performances of apes (Gorilla gorilla, Pan troglodytes, Pongo pygmaeus) and human children (Homo sapiens) in the floating peanut task. PLOS ONE, 6, e19555.

Haun, D. B. M., Call, J., Janzen, G., \& Levinson, S. C. (2006). Evolutionary psychology of spatial representations in the Hominidae. Current Biology, 16, 1736-1740.

Haun, D. B. M., Jordan, F. M., Vallortigara, G., \& Clayton, N. S. (2010). Origins of spatial, temporal and numerical cognition: Insights from comparative psychology. Trends in Cognitive Sciences, 14, 552-560.

Herrmann, E., Call, J., Hernández-Lloreda, M. V., Hare, B., \& Tomasello, M. (2007). Humans have evolved specialized skills of social cognition: The cultural intelligence hypothesis. Science, 317, 1360-1366.

Horner, V., \& Whiten, A. (2005). Causal knowledge and imitation/emulation switching in chimpanzees (Pan troglodytes) and children (Homo sapiens). Animal Cognition, 8, 164-181.

Johnson-Pynn, J., Fragaszy, D. M., \& Cummins-Sebree, S. (2003). Common territories in comparative and developmental psychology: Quest for shared means and meaning in behavioral investigations. International Journal of Comparative Psychology, $16,1-27$.
Kaminski, J., Call, J., \& Tomasello, M. (2008). Chimpanzees know what others know, but not what they believe. Cognition, 109(2), 224-234.

Liebal, K., Mueller, C., \& Pika, S. (2007). Gestural communication in nonhuman and human primates. Amsterdam: John Benjamins Publishing Company.

Okamoto-Barth, S., \& Call, J. (2008). Tracking and inferring spatial rotation by children and great apes. Developmental Psychology, 44, 1396-1408.

Rekers, Y., Haun, D., \& Tomasello, M. (2011). Children, but not chimpanzees, prefer to collaborate. Current Biology, 21, 17561758.

Rowe, N., Goodall, J., \& Mittermeier, R. A. (1996). The pictorial guide to the living primates. New York: East Hampton, Pogonias Press.

Tennie, C., Call, J., \& Tomasello, M. (2006). Push or pull: Imitation vs. emulation in great apes and human children. Ethology, 112, 1159-1169.

Tomasello, M., \& Call, J. (1997). Primate cognition. New York: Oxford University Press.

Warneken, F., \& Tomasello, M. (2006). Altruistic helping in human infants and young chimpanzees. Science, 311, 1301-1303.

\section{Bio Sketches}

Katja Liebal, Assistant Professor of Evolutionary Psychology in the Excellence Cluster Languages of Emotion, Department of Education and Psychology, Freie Universität Berlin. Research on multimodal communication of human and nonhuman primates with focus on their communication of emotions.

Daniel Haun, Ph.D., Group leader of Comparative Cognitive Anthropology Group (CoCoA) at the Max Planck Institute for Evolutionary Anthropology in Leipzig and Max Planck Institute for Psycholinguistics in Nijmegen. Research on cross-cultural variability of cognition, comparative and developmental social psychology, and comparative great ape cognition. 